\title{
Radiotherapy management of brain metastases using conventional linear accelerator
}

\author{
Marcel Matzenauera , David Vrana ${ }^{\mathrm{a}, \mathrm{b}, \mathrm{c}}$, Zuzana Vlachovaa ${ }^{\mathrm{a}}$, Karel Cwiertka ${ }^{\mathrm{a}}$, Ondrej Kalitad ${ }^{\mathrm{d}}$, Bohuslav Melichara, ${ }^{\mathrm{a}, \mathrm{b}}$
}

\begin{abstract}
Background and Aims. As treatments for primary cancers continue to improve life expectancy, unfortunately, brain metastases also appear to be constantly increasing and life expectancy for patients with brain metastases is low. Longer survival and improved quality of life may be achieved using localised radiological and surgical approaches in addition to low dose corticosteroids. Stereotactic brain radiotherapy is one rapidly evolving localized radiation treatment. This article describes our experience with stereotactic radiotherapy using a linear accelerator.

Methods. We reviewed patients treated with stereotactic radiotherapy, from the time of its introduction into daily practice in our Department of Oncology in 2014. We collected the data on patient treatment and predicted survival based on prognostic indices and actual patient outcome.

Results. A total of 10 patients were treated by stereotactic radiotherapy, in one case in combination with whole brain radiotherapy and hippocampal sparing. There was no significant treatment related toxicity during the treatment or follow-up and due to the small number of fractions, the overall tolerance of the treatment was excellent. The patient intrafractional movement in all cases was under $1 \mathrm{~mm}$ suggesting that $1 \mathrm{~mm}$ margin around the CTV to create the PTV is sufficient and also that patient immobilization using the thermoplastic mask compared with invasive techniques, is feasible. We also found that prognostic indices such as the Graded Prognostic Assessment provide accurate predictions of patient survival.
\end{abstract}

Conclusions. Based on our current evidence, patients with brain metastases fit enough, should be considered for stereotactic radiotherapy treatment.

Key words: brain, metastases, stereotactic, radiosurgery, radiotherapy, treatment

Received: April 15, 2016; Accepted with revision: August 10, 2016; Available online: September 13, 2016

http://dx.doi.org/10.5507/bp.2016.043

${ }^{a}$ Department of Oncology, Faculty of Medicine and Dentistry, Palacky University Olomouc, Czech Republic

${ }^{\circ}$ Institute of Molecular and Translational Medicine, Faculty of Medicine and Dentistry, Palacky University Olomouc and University Hospital Olomouc, Czech Republic

'Toxicogenomics Unit, National Institute of Public Health, Prague, Czech Republic

${ }^{d}$ Department of Neurosurgery, Faculty of Medicine and Dentistry, Palacky University Olomouc, Czech Republic

Corresponding author: David Vrana, e-mail: davvrana@gmail.com

\section{INTRODUCTION}

Any primary malignant tumour can spread to the brain but most common are those resulting from lung cancer, melanoma and renal cell carcinoma that represent more than $70 \%$ of brain metastases ${ }^{1,2}$.

\section{Prognosis and management}

There are currently no clear recommendations for appropriate management of patients with brain metastases and several prognostic factors should be considered. Two fundamental approaches to prognostic assessment have been introduced to guide appropriate treatment selection. The, first Recursive Partitioning Analysis (RPA) was introduced in 1997. RPA relies on the assessment of three treatment-related variables including age, Karnofsky performance status (KPS) and the extent of extracranial disease. In the original report that was based on analysis of 1200 patients, three prognostic classes were defined. Class 1 consisted of patients with KPS over 70, age below 65 years, controlled primary tumor and with the brain being the only metastatic site (isolated brain metastases). Class 3 included patients with KPS below 70, with the remaining patients categorized as class 2 . The median survival of class 1, class 2 and class 3 patients was 7.1, 4.2 and 2.3 months, respectively ${ }^{3}$. In 2011, a new prognostic index was proposed aiming to eliminate the main RPA limitation which was missing information about the primary site of the tumor, the Graded Prognostic Assessment (GPA). In the first report, 3,940 patients were analyzed for prognostic factors associated with the outcomes by primary site and treatment. This analysis concluded, as expected that prognostic factors are different for different tumor types. The GPA index ranges from 0.0 to 4.0, with higher scores indicating longer overall survival. Consequently, the approach to treatment selection should be individualized based on the expected median survival. Clinicians should be encouraged to use this assessment tool for stratifying patients when deciding the treatment approach. Patients with a GPA score with 0 to 1.0 are therefore considered to have poor prognosis while patients with a GPA score 1.0 to 4.0 are considered to have a favorable prognosis ${ }^{4}$. 
Stereotactic brain radiotherapy (SRT) using linear accelerator (LA) is currently a rapidly evolving radiotherapy technique. The main difference between SRT using LA and radiotherapy with conventional fractionation is the use of a small number of fractions (usually one to six), high radiation dose per fraction and steep dose gradient. The use of LA to perform the SRT enables all centers equipped with LA to offer this treatment approach resulting in significant reduction in cost and more comfort for the patients.

\section{METHODS}

We reviewed patients treated by SRT in the Department of Oncology, University Hospital Olomouc, Czech Republic selecting the patients treated for brain metastatic disease. For the treatment, the LA Elekta Synergy (Elekta Instrument AB Stockholm, Sweden) with Volumetric Arc Therapy (VMAT) technique and Monaco (Elekta Instrument AB Stockholm,Sweden) planning system with Monte Carlo calculation algorithm for treatment planning were used. The gross tumor volume (GTV) was delineated after fusion of planning scan with magnetic resonance imaging (MRI) utilizing T1 weighted images with gadolinium contrast. No additional margin was added to create the clinical target volume (CTV) and the CTV was expanded by $1 \mathrm{~mm}$ or $2 \mathrm{~mm}$ from the planning target volume (PTV). A dose of 21-36 Gy usually over 3-5 consecutive days was prescribed in $60-85 \%$ isodose. The prescribed dose was based on the size, number, location of the metastases and also previous radiotherapy. The treatment plans were assessed for conformity (calculated as a ratio of volume covered by the $100 \%$ isodose and volume of the PTV covered by the same isodose) (ref. ${ }^{5}$ ), dose gradient (calculated as the ratio of volume covered by prescribed dose and volume covered by half of the prescribed dose) (ref. ${ }^{6}$ ) and also for doses in organs at risk (OAR) more specifically in optic chiasma, optic nerve, retina (contouring whole eye bulb), lenses and brain stem. Three cone beam CTs (CBCT) were performed to assure proper patient positioning during the radiotherapy. All patients are followed to assess possible acute and late toxicity by a radiation oncologist.

\section{RESULTS}

SRT was introduced into daily practice in the Department of Oncology, in the beginning of 2014 and so far 57 patients have been irradiated, including 10 treated for brain metastases. Patient characteristics, treatment type and outcomes are summarized in Table 1. All patients were assessed using the RPA and GPA score before the treatment decision, as recommended above. However, irrespective of the final calculated score, the treating physician's clinical experience and opinion were also taken into account in selecting the treatment strategy. All patients were discussed in multidisciplinary teams. Low dose corticosteroids were recommended for patients during and after the course of SRT. The data indicate that RPA and GPA correctly predicted the clinical outcome.

There was no significant treatment related toxicity observed during the treatment or follow-up and due to low number of fractions the overall tolerance of the treatment by patients was excellent. The patient intrafractional movement in all cases was under $1 \mathrm{~mm}$ suggesting that $1 \mathrm{~mm}$ margin around the CTV to create the PTV is sufficient and also that the patient immobilization using the thermoplastic mask comparing with invasive techniques is feasible.

\section{DISCUSSION}

Reviewing the patient outcomes in this retrospective study, patient with a GPA 0 had the poorest prognosis with survival in days rather than months and best supportive care with the use of corticosteroids, more specifically dexamethasone (due to its low mineralocorticoid effect) is the best treatment option. Corticosteroids can alleviate the symptoms of brain edema within hours ${ }^{7}$. Patients with intermediate prognosis i.e. patients with GPA 1, whole brain radiotherapy (WBRT) should be considered a standard treatment. However, data on the purported benefit of WBRT are highly controversial. The QUARTZ study found no significant benefit of adding WBRT in non-small cell lung cancer (NSCLC) patients ${ }^{8}$ and Nieder et al. also confirmed that there was no significant benefit of WBRT with one exception and that was a group of patients with small cell lung cancer. This small sub-group benefited from a WBRT of $30 \mathrm{~Gy}$ ( ref. $^{9}$ ). Our results demonstrated that patients with GPA 3 had relatively favorable prognosis with expected survival in months. In selecting an appropriate treatment strategy for this subgroup of patients, the extent of cranial disease should be assessed as the number and size of brain metastases have significant impact on the decision. Surgery provides rapid removal of the source of perifocal edema and is especially useful for patients with tumors larger than $3 \mathrm{~cm}$, particularly in posterior fossa ${ }^{10}$. It also provides a major benefit in the ability to assess the tumor histology which may significantly influence further decisions about the systemic treatment. The benefit of surgery was demonstrated in two studies of patients with solitary brain metastasis ${ }^{11-12}$. SRS/SRT is characterized by highly conformal dose delivery, steep dose gradient at tumor margin and by non-homogenous dose distribution inside the irradiated volume which allows very accurate treatment in well circumscribed lesions with large dose per fraction. The radiotherapy treatment may be delivered using Gamma Knife, CyberKnife system or conventional linear accelerator as demonstrated in the present series. A summary of studies comparing SRT/SRS versus surgery in brain metastases is provided in Table 2.

There is strong evidence that SRT is more appropriate in combination with WBRT than with WBRT alone. It has been demonstrated that SRS boost to WBRT significantly prolongs overall survival ${ }^{21}$. When SRT/SRS with or without WBRT are compared, the data are inconclusive $^{22-23}$. This is in line with our practice as shown by the 

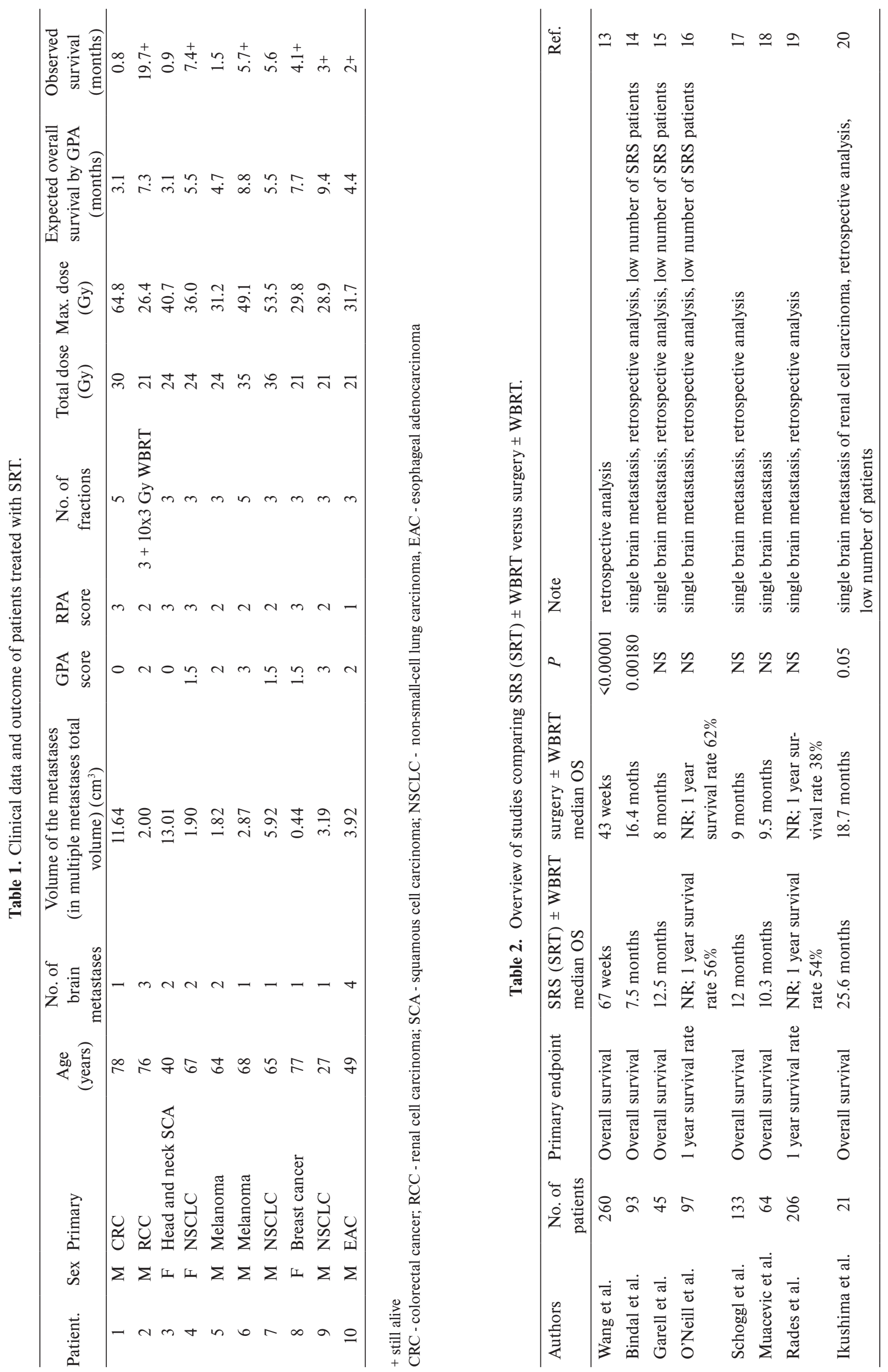
fact that only in one patient SRT was followed by WBRT. WBRT exposes the patient to significant toxicity. Some authors have suggested that the cognitive decline after WBRT is most probably caused by the radiation damage to the hippocampus ${ }^{24}$. In one patient with renal cell carcinoma, we decided to irradiate the brain metastases by SRT utilizing the ablative effect of SRT and at the same time irradiate the whole brain to decrease the probability of disease recurrence outside the SRT treatment sites. We used a novel technique when the hippocampal structures are spared during the radiotherapy planning and deliveryHippocampal Avoidance Whole Brain Radiotherapy. This method was assessed in the RTOG 0933 trial, which compared neurological deterioration in patients with brain metastases treated with WBRT with or without the hippocampal sparing technique. The group with no sparing had a $30 \%$ mean relative decline of baseline functions as assessed by this test while the group with sparing of hippocampus showed a $7 \%$ decline from baseline at 4 months $(P<.001)$ confirming the neurocognitive sparing potential of this novel approach ${ }^{25}$. After 20 months follow-up, the patient is still alive without any significant cognitive difficulties. This case report was recently published ${ }^{26}$. However this technique is very time consuming and depends on the experience of the treating oncologist.

This retrospective review of treated patients, allows us to conclude that GPA and RPA both provide reasonable estimates of prognosis for treatment strategy selection. Our experience also indicates that these two prognostic indices provided similar results for patient prognosis. Long-term disease control and survival can be achieved in individual patients but the interpretation of the data is limited by short follow-up.

\section{CONCLUSION}

Utilizing conventional linear accelerator for stereotactic brain radiotherapy is a feasible and safe technique and should not be forgotten during the treatment strategy planning for patients with brain metastatic disease.

Acknowledgement: IGA_LF_2016_014.

Author contributions: Paper design: MM, DV. Patient treatment: DV, OK, KC. Patient data analysis: KC, OK, ZV, DV. Manuscript writing: BM,MM, DV.

Conflict of interest statement: The authors state that there are no conflicts of interest regarding the publication of this article.

\section{REFERENCES}

1. Wen PY, Loeffler JS. Management of brain metastases. Oncology (WillistonPark) 1999;13(7): 941-54,957-61; discussion 961-2, 9. Review.

2. Barnholtz-Sloan JS, Sloan AE, Davis FG, Vigneau FD, Lai P, Sawaya RE. Incidence proportions of brain metastases in patients diagnosed (1973 to 2001) in the Metropolitan Detroit Cancer Surveillance System. J Clin Oncol 2004;22(14):2865-72.

3. Gaspar L, Scott C, Rotman M, Asbell S, Phillips T, Wasserman T,
McKenna WG, Byhardt R. Recursive partitioning analysis (RPA) of prognostic factors in three Radiation Therapy Oncology Group (RTOG) brain metastases trials. Int J Radiat Oncol Biol Phys 1997;37(4):745-51.

4. Sperduto PW, Chao ST, Sneed PK, Luo X, Suh J, Roberge D, Bhatt A, Jensen AW, Brown PD, Shih H, Kirkpatrick J, Schwer A, Gaspar LE, Fiveash JB, Chiang V, Knisely J, Sperduto CM, Mehta M. Diagnosisspecific prognostic factors, indexes, and treatment outcomes for patients with newly diagnosed brain metastases: a multi-institutional analysis of 4,259 patients. Int J Radiat Oncol Biol Phys 2010;77(3):655-61.

5. Prescribing recording and reporting photon-beam therapy (Supplement to ICRU Report 50) Bethesda, MD, USA: ICRU Publications; International Commission on Radiation Units and Measurements; 1999. ICRU Report 62.

6. Paddick I, Lippitz B. A simple dose gradient measurement tool to complement the conformity index. J Neurosurg 2006;105 Suppl:194-201.

7. Alberti E, Hartmann A, Schütz HJ, Schreckenberger F. The effect of large doses of dexamethasone on the cerebrospinal fluid pressure in patients with supratentorial tumors. J Neurol 1978;217(3):173-81.

8. Langley RE, Stephens RJ, Nankivell M, Pugh C, Moore B, Navani N, Wilson P, Faivre-Finn C, Barton R, Parmar MK, Mulvenna PM; QUARTZ Investigators. Interim data from the Medical Research Council QUARTZTrial: does whole brain radiotherapy affect the survival and quality of life of patients with brain metastases from non-small cell lung cancer? Clin Oncol (R Coll Radiol) 2013;25(3):e23-30.

9. Nieder C, Norum J, Dalhaug A, Aandahl G, Pawinski A. Radiotherapy versus best supportive care in patients with brain metastases and adverse prognostic factors. Clin Exp Metastasis 2013;30(6):723-9.

10. Vogelbaum MA, Suh JH. Resectable brain metastases. J Clin Oncol 2006;24(8):1289-94.

11. Patchell RA, Tibbs PA, Walsh JW, Dempsey RJ, Maruyama Y, Kryscio RJ, Markesbery WR, Macdonald JS, Young B. A randomized trial of surgery in the treatment of single metastases to the brain. N Engl J Med 1990;322(8):494-500.

12. Vecht CJ, Haaxma-Reiche $H$, Noordijk EM, Padberg GW, Voormolen JH, Hoekstra FH, Tans JT, Lambooij N, Metsaars JA, Wattendorff AR. Treatment of single brain metastasis: radiotherapy alone or combined with neurosurgery? Ann Neurol 1993;33(6):583-90.

13. Wang LG, Guo Y, Zhang X, Song SJ, Xia JL, Fan FY, Shi M, Wei LC. Brain metastasis: experience of the Xi-Jing hospital. Stereotact Funct Neurosurg 2002;78(2):70-83.

14. Bindal AK, Bindal RK, Hess KR, Shiu A, Hassenbusch SJ, Shi WM, Sawaya $R$. Surgery versus radiosurgery in the treatment of brain metastasis. J Neurosurg 1996;84(5):748-54.

15. Garell PC, Hitchon PW, Wen BC, Mellenberg DE, Torner J. Stereotactic radiosurgery versus microsurgical resection for the initial treatment of metastatic cancer to the brain. J Radiosurg 1999;2(1):1-5.

16. O'Neill BP, Iturria NJ, Link MJ, Pollock BE, Ballman KV, O'Fallon JR. A comparison of surgical resection and stereotactic radiosurgery in the treatment of solitary brain metastases. Int J Radiat Oncol Biol Phys 2003;55(5):1169-76.

17. Schöggl A, Kitz K, Reddy M, Wolfsberger S, Schneider B, Dieckmann $\mathrm{K}$, Ungersböck K. Defining the role of stereotactic radiosurgery versus microsurgery in the treatment of single brain metastases. Acta Neurochir (Wien) 2000;142(6):621-6.

18. Muacevic A, Wowra B, Siefert A, Tonn JC, Steiger HJ, Kreth FW. Microsurgery plus whole brain irradiation versus Gamma Knife surgery alone for treatment of single metastases to the brain: a randomized controlled multi centre phase III trial. J Neurooncol 2008;87(3):299-307.

19. Rades D, Bohlen G, Pluemer A, Veninga T, Hanssens P, Dunst J, Schild $\mathrm{SE}$. Stereotactic radiosurgery alone versus resection plus wholebrain radiotherapy for 1 or 2 brain metastases in recursive partitioning analysis class 1 and 2 patients. Cancer 2007;109(12):2515-21.

20. Ikushima H, Tokuuye K, Sumi M, Kagami Y, Murayama S, Ikeda H, Tanaka M, Oyama H, Shibui S, Nomura K. Fractionated stereotactic radiotherapy of brain metastases from renal cell carcinoma. Int J Radiat Oncol Biol Phys 2000;48(5):1389-93.

21. Andrews DW, Scott CB, Sperduto PW, Flanders AE, Gaspar LE, Schell MC, Werner-Wasik M, Demas W, Ryu J, Bahary JP, Souhami L, Rotman M, Mehta MP, Curran WJ Jr. Whole brain radiation therapy with or without stereotactic radiosurgery boost for patients with one to 
three brain metastases: phase III results of the RTOG 9508 randomised trial. Lancet 2004;363(9422):1665-72.

22. Kocher M, Wittig A, Piroth MD, Treuer $H$, Seegenschmiedt $H$, Ruge $M$, Grosu AL, Guckenberger M. Stereotactic radiosurgery for treatment of brain metastases. A report of the DEGRO Working Group on Stereotactic Radiotherapy. Strahlenther Onkol 2014;190(6):521-32

23. Aoyama H, Shirato H, Tago M, Nakagawa K, Toyoda T, Hatano K, Kenjyo M, Oya N, Hirota S, Shioura H, Kunieda E, Inomata T, Hayakawa K, Katoh N, Kobashi G. Stereotactic radiosurgery plus whole-brain radiation therapy vs stereotactic radiosurgery alone for treatment of brain metastases: a randomized controlled trial. JAMA 2006;295(21):2483-91.

24. Mizumatsu S, Monje ML, Morhardt DR, Rola R, Palmer TD and Fike
JR. Extreme sensitivity of adult neurogenesis to low doses of X-irradiation. Cancer Res 2003;63:4021-7.

25. Gondi V, Pugh SL, Tome WA, Caine C, Corn B, Kanner A, Rowley H, Kundapur V, DeNittis A, Greenspoon JN, Konski AA, Bauman GS, Shah S, Shi W, Wendland M, Kachnic L, Mehta MP. Preservation of memory with conformal avoidance of the hippocampal neural stem-cell compartment during whole-brain radiotherapy for brain metastases (RTOG 0933): a phase II multi-institutional trial. J Clin Oncol 2014;32(34):3810-6.

26. Vrana D, Studentova H, Matzenauer M, Vlachova Z, Cwierka K Gremlica D, Kalita O. Treatment of brain metastases of renal cell cancer with combined hypofractionated stereotactic radiotherapy and whole brain radiotherapy with hippocampal sparing. Oncology Letters 2016;11(6):3777-81. 